\title{
Correction of Hyperinsulinemia by Glyburide Treatment in Nondiabetic Patients with Thalassemia Major
}

\author{
TIMOTHY W. JONES, SUSAN D. BOULWARE, SONIA CAPRIO, PETER MERKEL, \\ STEPHANIE A. AMIEL, HOWARD A. PEARSON, ROBERT S. SHERWIN, AND \\ WILLIAM V. TAMBORLANE \\ Departments of Pediatrics and Internal Medicine and the General Clinical Research Centers of Yale University, \\ New Haven, Connecticut 06510
}

\begin{abstract}
Hyperinsulinemia and insulin resistance precede the development of diabetes in patients with thalassemia major on hypertransfusion/desferoxamine therapy. To examine whether these early metabolic defects could be reversed, seven nondiabetic patients with thalassemia $(17 \pm 4 \mathrm{y})$ were studied for $12 \mathrm{mo}$ before and during $12 \mathrm{mo}$ of low-dose treatment with glyburide $(1.25$ to $3.75 \mathrm{mg} / \mathrm{d})$, a second-generation oral hypoglycemic agent. Plasma glucose responses to oral glucose $(1.75 \mathrm{~g} / \mathrm{kg}$ body weight) were normal before and after glyburide. Plasma insulin responses were markedly increased before glyburide therapy (area under insulin response curve $86 \pm 15$ and $96 \pm$ 15 versus $40 \pm 5 \mathrm{nmol} / \mathrm{min} / \mathrm{L}$ in normal controls, $p<$ 0.001). However, insulin responses to glucose fell significantly after $3 \mathrm{mo}$ of glyburide (to $52 \pm 7 \mathrm{nmol} / \mathrm{min} / \mathrm{L}, p<$ 0.05 versus pretreatment) and were normalized after $12 \mathrm{mo}$ $(42 \pm 7 \mathrm{nmol} / \mathrm{min} / \mathrm{L}, p=\mathrm{NS}$ versus controls). The rate of insulin-stimulated glucose metabolism during euglycemic insulin clamps $\left(40 \mathrm{mU} / \mathrm{m}^{2} / \mathrm{min}\right)$ was low in the patients before treatment $\left(163 \pm 10\right.$ versus $215 \pm 17 \mathrm{mg} / \mathrm{m}^{2} / \mathrm{min}$ in controls, $p<0.05$ ) and increased to $205 \pm 30 \mathrm{mg} / \mathrm{m}^{2} / \mathrm{min}$ after 3 mo of glyburide. The treatment was well tolerated. In conclusion, in nondiabetic, hyperinsulinemic, thalassemic patients, chronic glyburide therapy normalizes insulin responses to oral glucose. To the extent that insulin hypersecretion contributes to the development of diabetes in thalassemia, glyburide therapy may provide a means of postponing this complication of the disease. (Pediatr Res 33: 497-500, 1993)
\end{abstract}

The survival and quality of life of children with thalassemia major has greatly improved with hypertransfusion and iron chelation therapy (1). Nevertheless, many patients continue to develop complications from chronic iron overload. Of these, diabetes mellitus is important because it imposes a high risk for other complications (2). Although the development of diabetes in thalassemia has been attributed to insulin deficiency due to the direct toxic effects of iron deposited in the pancreatic islets, recent studies (3) have demonstrated that thalassemic patients exhibit hyperinsulinemia in conjunction with insulin resistance

Received May 14, 1992; accepted January 13, 1993.

Correspondence: Timothy W. Jones, Department of Endocrinology and Diabetes, Princess Margaret Hospital for Children, Box D184, Perth, Western Australia.

Dr. Jones is the recipient of the Sammy Davis, Jr. Scholarship (TVW Telethon, W. Australia). Drs. Boulware and Caprio are recipients of a Postdoctoral Fellowship and Career Development Award (respectively) from the Juvenile Diabetes Foundation International. Supported by Grants DK 20495, RR 06022, and RR 00215 from the National Institute of Health and a grant from Novo-Nordisk, Inc. before the appearance of insulin deficiency and overt diabetes. These findings suggest that compensatory hypersecretion of insulin may be a key factor leading to B-cell exhaustion and may itself contribute to the development of diabetes in thalassemia.

Oral hypoglycemic agents (sulfonylureas) act in part by improving sensitivity to endogenous insulin (4-6), but in our practice they have been ineffective as therapy in patients with thalassemia once insulinopenia and overt diabetes have developed. On the other hand, it has not been determined whether these agents might improve insulin sensitivity and reduce excessive insulin secretion during the earlier insulin-resistant, hyperinsulinemic phase of the disease. To examine this question, we measured insulin responses to oral glucose and assessed insulin sensitivity (using the euglycemic insulin clamp technique) in young, nondiabetic patients with thalassemia before and during 12 mo therapy with glyburide, a second-generation sulfonylurea. Our findings indicate that glyburide sharply lowers insulin responses to oral glucose in these patients to values observed in normal control subjects without adversely affecting glucose tolerance.

\section{MATERIALS AND METHODS}

Subjects. Patients with thalassemia were selected from those treated at the Thalassemia Clinic of Yale-New Haven Medical Center. Those eligible for study were at least $12 \mathrm{y}$ old and had no evidence of diabetes or glucose intolerance.

Table 1 summarizes the clinical characteristics of the patients at baseline before the start of therapy with glyburide. All were treated with transfusions $(15 \mathrm{~mL}$ of packed erythrocytes $/ \mathrm{kg}$ of body weight) every 4 to $6 \mathrm{wk}$ to maintain $\mathrm{Hb}(>90$ to $100 \mathrm{~g} / \mathrm{L})$, desferoxamine $(1.5$ to $2.0 / \mathrm{kg} / \mathrm{d}$ for up to $6 \mathrm{~d} / \mathrm{wk}$, given by continuous s.c. infusion over 8 to $10 \mathrm{~h})$, and ascorbic acid (100 mg p.o. before each desferoxamine infusion). None were receiving any other medication.

The protocol was approved by the Human Investigation Committee of the Yale University School of Medicine, and informed written consent was obtained from all patients and the parents of children less than $18 \mathrm{y}$ of age.

Procedures. Thalassemic and control subjects were admitted to the Children's Clinical Research Center for performance of glucose tolerance tests and euglycemic insulin clamp studies. In the thalassemic patients, the studies were timed to coincide with scheduled blood transfusions that were given at the conclusion of the experimental procedure. In the patients, both procedures were performed during a single hospital admission; the glucose tolerance test was performed on the first full hospital day and the euglycemic clamp study on the third hospital day.

Oral glucose tolerance test. Studies were performed on the morning after an overnight fast of 10 to $12 \mathrm{~h}$. Glucose was 
Table 1. Clinical characteristics of thalassemic patients before start of treatment

\begin{tabular}{ccccccccc}
\hline $\begin{array}{c}\text { Patients } \\
(n=7)\end{array}$ & Sex & $\begin{array}{c}\text { Age } \\
(\mathrm{y})\end{array}$ & $\begin{array}{c}\mathrm{Wt} \\
(\mathrm{kg})\end{array}$ & $\begin{array}{c}\mathrm{Ht} \\
(\mathrm{cm})\end{array}$ & $\begin{array}{c}\text { BMI* } \\
\left(\mathrm{kg} / \mathrm{m}^{2}\right)\end{array}$ & $\begin{array}{c}\text { Tanner stage } \\
(\text { pubic hair })\end{array}$ & $\begin{array}{c}\text { Fasting glucose } \\
(\mathrm{mM})\end{array}$ & $\begin{array}{c}\text { Fasting insulin } \\
(\mathrm{pM})\end{array}$ \\
\hline 1 & $\mathrm{~F}$ & 15 & 41 & 150 & 18.2 & 4 & 4.8 & 102 \\
2 & $\mathrm{~F}$ & 21 & 47 & 152 & 20.9 & 5 & 2.7 & 120 \\
3 & $\mathrm{~F}$ & 12 & 33 & 127 & 20.5 & 2 & 5.3 & 96 \\
4 & $\mathrm{M}$ & 18 & 67 & 164 & 24.9 & 4 & 5.2 & 102 \\
5 & $\mathrm{~F}$ & 20 & 57 & 162 & 21.7 & 5 & 5.2 & 126 \\
6 & $\mathrm{~F}$ & 21 & 50 & 149 & 22.6 & 5 & 4.7 & 174 \\
7 & $\mathrm{~F}$ & 14 & 57 & 153 & 24.3 & 4 & $4.9 \pm 0.3$ & $116 \pm 30$ \\
\hline
\end{tabular}

* BMI, body mass index.

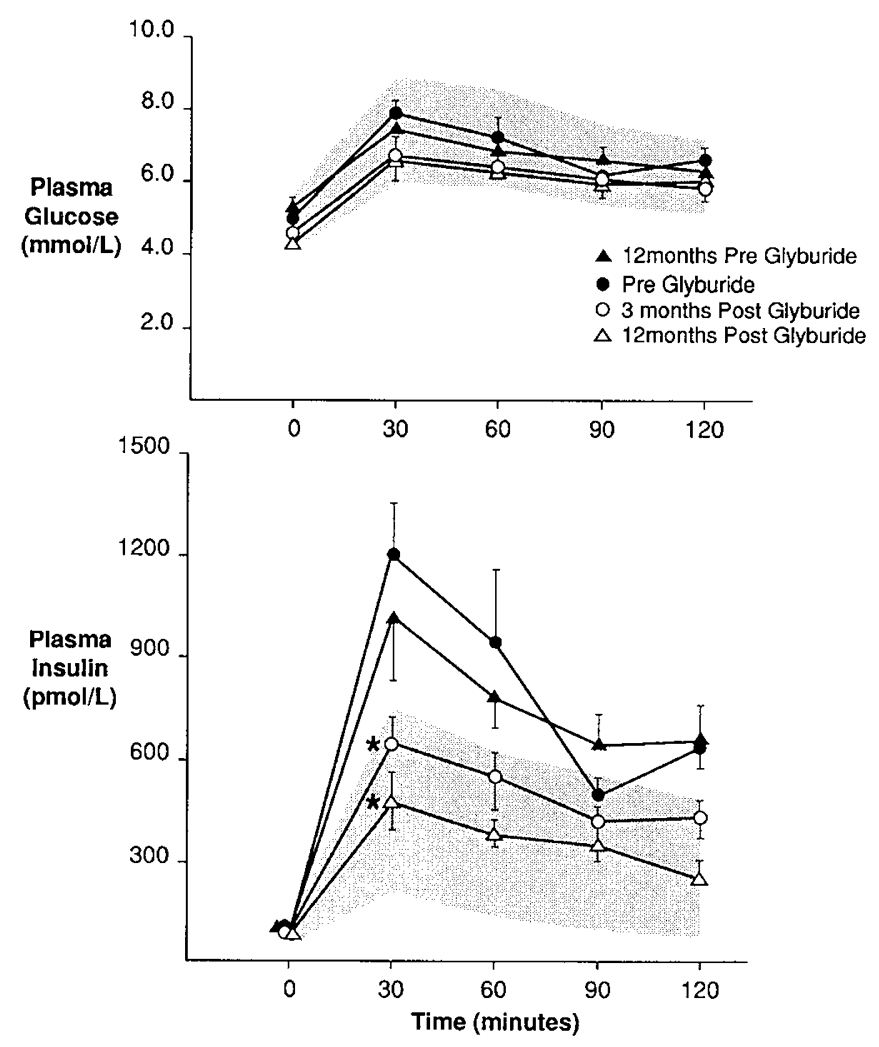

Fig. 1. Mean \pm SEM plasma glucose and insulin levels in patients 12 mo $(\boldsymbol{\Lambda})$ before and immediately $(\boldsymbol{\bullet})$ before glyburide therapy and after 3 $(O)$ and $12(\triangle)$ mo of glyburide therapy. The shaded areas indicate values (mean $\pm \mathrm{SD}$ ) in normal control subjects. Plasma insulin values at 30 min were significantly lower than pretreatment values $\left({ }^{*}, p<0.05\right.$ ) after 3 and 12 mo of therapy.

ingested in a dose of $1.75 \mathrm{~g} / \mathrm{kg}$, up to a maximum of $100 \mathrm{~g}$, and blood samples were obtained from an indwelling venous catheter at $-15,0,30,60,90$, and 120 min for measurement of plasma glucose and insulin. This procedure was performed on four occasions: 1 y before $(-12 \mathrm{mo})$ and immediately before glyburide therapy $(0 \mathrm{mo})$ and after 3 and 12 mo of treatment. Results were compared with values from 21 healthy age-matched $(17 \pm 6 \mathrm{y}$; 12 females, nine males), nonobese control subjects.

Euglycemic insulin clamp studies. After an overnight fast, two i.v. catheters were inserted: one in an antecubital vein for administration of insulin and glucose and the other in a vein of the hand of the contralateral arm for blood sampling. The hand chosen for blood sampling was placed in a heated box $(60$ to $\left.65^{\circ} \mathrm{C}\right)$ to "arterialize" venous blood (7). After a rest period of at least $30 \mathrm{~min}$, baseline fasting blood samples were obtained for measurement of plasma glucose and insulin. The techniques of the euglycemic insulin clamp have been described in detail elsewhere (8) and are briefly outlined below.

A primed continuous infusion of regular human insulin
(Novo-Nordisk, Princeton, NJ) was administered at a dose of 40 $\mathrm{mU} / \mathrm{m}^{2}$ of body surface area/min for $120 \mathrm{~min}$. In each subject, the plasma glucose concentration was "clamped" at approximately $5.0 \mathrm{mM}$ by simultaneous infusion of a $20 \%$ glucose solution. The glucose infusion rate was adjusted to maintain euglycemia on the basis of plasma glucose measurements made at the bedside every $5 \mathrm{~min}$. Blood was also obtained at 20 -min intervals for insulin measurements.

Euglycemic insulin clamps were performed in the patients before and after 3 mo of therapy with glyburide and the results compared with those obtained from studies performed under identical conditions in seven normal control subjects (six females and one male) matched with the patients for age $(18 \pm 5 \mathrm{y})$ and body mass index $\left(21.1 \pm 1.1 \mathrm{~kg} / \mathrm{m}^{2}\right)$. To limit the burden of their participation in the study, the patients were not asked to undergo an additional clamp study after 12 mo of treatment.

Glyburide treatment. After baseline procedures were completed, glyburide was administered in an initial dose of $1.25 \mathrm{mg} /$ $\mathrm{d}$. The dose was increased by $1.25 \mathrm{mg} / \mathrm{d}$ weekly to a maximum of $5 \mathrm{mg} / \mathrm{d}$ or until mild symptomatic or biochemical (fingerstick blood glucose at home) hypoglycemia intervened. The patients that developed hypoglycemia were maintained on a daily dose of glyburide that was $1.25 \mathrm{mg}$ less than that which caused hypoglycemia. All patients completed the full 12 mo of therapy. No change in dietary content was recommended, but patients were advised not to miss meals.

Determinations. Plasma glucose was measured according to the glucose oxidase method with a glucose analyzer (Beckman Instruments, Fullerton, CA). Insulin was measured by RIA (Ventrex, ME), plasma ferritin was measured by a solid radioimmunometric assay procedure (Ramco Laboratories, Houston, TX), and fructosamine by Nichols Institute (San Juan Capistrano, CA).

Analysis. Clinical data (Table 1) are expressed as the mean \pm $\mathrm{SD}$, all other data as the mean \pm SEM. Treatment effects involving repeated measures within the patient group and comparisons with the control group were made using analysis of variance. Other comparisons within the patient group were made using paired two-tailed $t$ tests.

Under steady state conditions of euglycemia during the insulin clamp study, the rate of glucose infusion provides an index of insulin-stimulated glucose metabolism. This rate (expressed in $\mathrm{mg} / \mathrm{m}^{2}$ of body surface area/min) was calculated at $20-\mathrm{min}$ intervals and adjusted for deviations from the target plasma glucose level of $5.0 \mathrm{mM}$ as previously described (8). The average glucose infusion rate required during the last $60 \mathrm{~min}$ of each clamp study was used for comparison.

\section{RESULTS}

Oral glucose tolerance tests. Figure 1 compares the plasma glucose and insulin responses with oral glucose in the patients before and after glyburide administration with the range of values in normal control subjects. As expected from the inclusion criteria for entry into the study, both the fasting plasma glucose and the plasma glucose responses after glucose ingestion were 


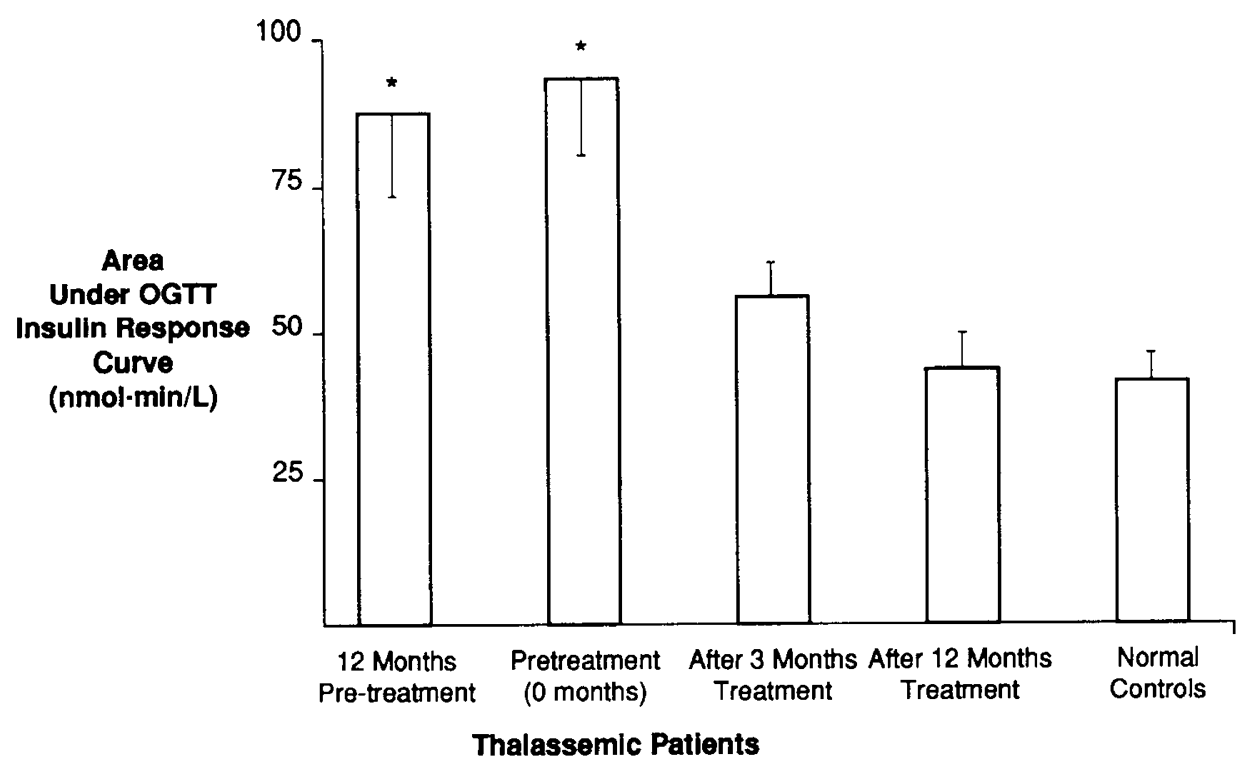

Fig. 2. Areas under the insulin response curve (mean $\pm \mathrm{SEM}$ ) in normal control subjects and thalassemic patients before treatment and after 3 and 12 mo of glyburide therapy. Pretreatment values were significantly higher $(*, p<0.01)$ than those of normal controls and those of patients during therapy. OGTT, oral glucose tolerance test.

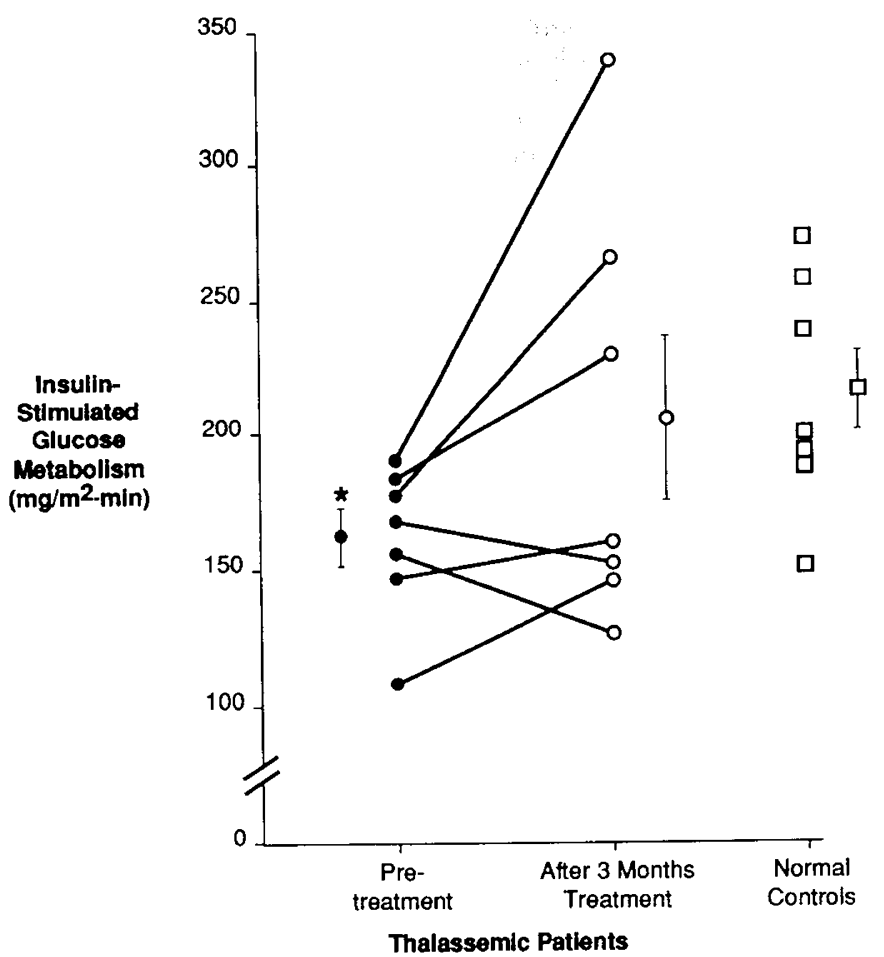

Fig. 3. Rates of insulin-stimulated glucose metabolism in thalassemic patients before $(\bullet)$ and after $(O) 3$ mo of glyburide therapy and in normal controls $(\square)$. Values before treatment were significantly lower than those of normal controls. ${ }^{*}, p<0.05$.

within the normal range in the patients before glyburide treatment at both -12 and 0 mo of study. Three mo after institution of glyburide therapy, glucose levels after oral glucose were slightly but not significantly lower and remained unchanged after 12 mo of treatment (Fig. 1).

Although fasting insulin levels did not change after glyburide therapy, insulin responses to oral glucose were markedly altered (Fig. 1). Twelve mo before treatment, insulin responses induced by glucose ingestion were sharply increased as compared with normal controls, and an even slightly greater insulin response to oral glucose was observed just before treatment with glyburide
( $0 \mathrm{mo})$. In contrast, after 3 mo of glyburide therapy, there was a marked reduction of glucose-stimulated insulin levels, particularly during the first $60 \mathrm{~min}$ after glucose ingestion (e.g. plasma insulin at $30 \mathrm{~min}$ fell from $1200 \pm 156$ to $636 \pm 162 \mathrm{pM}$ after 3 mo of glyburide, $p<0.05$ ). Moreover, after $12 \mathrm{mo}$, glucosestimulated insulin levels fell to values that were indistinguishable from those in normal control subjects. Peak insulin levels were also normalized with glyburide, falling from $1416 \pm 222$ at baseline to $702 \pm 144 \mathrm{pM}$ after $3 \mathrm{mo}(p<0.05)$ and to $504 \pm$ 90 after 12 mo versus $498 \pm 48$ pM in controls.

In keeping with these findings, the area under the insulin response curve during the glucose tolerance test (Fig. 2) increased slightly during the 12-mo observation period before treatment (from $86 \pm 15$ to $96 \pm 15 \mathrm{nmol} / \mathrm{min} / \mathrm{L}$ ), reaching values that were 2 -fold greater than those in normal control subjects ( $40 \pm$ $5 \mathrm{nmol} / \mathrm{min} / \mathrm{L}, p<0.01)$. This area was reduced after 3 mo to $52 \pm 7 \mathrm{nmol} / \mathrm{min} / \mathrm{L}(p<0.01$ versus preglyburide $)$ and fell further to $42 \pm 7$ after 12 mo ( $p=$ NS versus controls).

Euglycemic insulin clamp studies. Steady state plasma insulin levels during the euglycemic clamp studies were similar in the patients before $(438 \pm 18 \mathrm{pM})$ and after 3 mo of glyburide (402 $\pm 24 \mathrm{pM})$ and in the controls $(522 \pm 42)$. Mean plasma glucose levels during the clamp procedures remained within $5 \%$ of basal levels in all subjects. As expected (3), the rate of exogenous glucose infusion required to maintain this euglycemic plateau in the patients at entry into the study $\left(163 \pm 10 \mathrm{mg} / \mathrm{m}^{2} / \mathrm{min}\right)$ was significantly less than that in control subjects $\left(215 \pm 17 \mathrm{mg} / \mathrm{m}^{2} /\right.$ min, $p<0.05$ ) (Fig. 3). After 3 mo of treatment with glyburide, insulin-stimulated glucose metabolism rose in the patients to values $\left(205 \pm 30 \mathrm{mg} / \mathrm{m}^{2} / \mathrm{min}\right)$ that were similar to those in normal controls. As shown in Figure 3, the change in insulin responsiveness after treatment was variable, and, as a result, the mean increase with treatment did not reach statistical significance.

Side effects of glyburide therapy. Mild symptoms of hypoglycemia (weakness, shakiness) were reported by four patients during the initial adjustment of therapy, and these did not recur after subsequent dosage reduction. No other side effects from the 12 mo of glyburide therapy were noted, including changes in liver function tests. As shown in Table 2, there were no significant changes in height, weight, relative adiposity, or hematologic status either before or after treatment. The modest decrease in fructosamine values was not statistically significant. 
Table 2. Changes in clinical and biochemical parameters during study*

\begin{tabular}{lcrrr} 
& \multicolumn{3}{c}{ Mo of study } \\
\cline { 3 - 5 } & -12 & 0 & 3 & 12 \\
\hline $\mathrm{Wt}(\mathrm{kg})$ & $49 \pm 4$ & $50 \pm 4$ & $51 \pm 4$ & $51 \pm 4$ \\
$\mathrm{Ht}(\mathrm{cm})$ & $149 \pm 4$ & $151 \pm 4$ & $151 \pm 4$ & $152 \pm 4$ \\
$\mathrm{BMI}\left(\mathrm{kg} / \mathrm{m}^{2}\right)$ & $22 \pm 1$ & $10.3 \pm 0.4$ & $22 \pm 1$ & $22 \pm 1$ \\
$\mathrm{Hb}(\mathrm{g})$ & $10.6 \pm 0.6$ & $4037 \pm 1127$ & $10.6 \pm 0.2$ & $10.5 \pm 0.3$ \\
Ferritin $(\mathrm{g} / \mathrm{L})$ & $4128 \pm 1407$ & $1.9 \pm 0.2$ & $5214 \pm 1970$ \\
Fructosamine $(\%) \dagger$ & & & $1.7 \pm 0.2$ \\
\hline
\end{tabular}

* Data are presented as mean \pm SEM. BMI, body mass index.

$\dagger$ Normal range, 1.5 to $2.7 \%$.

\section{DISCUSSION}

The current study demonstrates that long-term treatment with glyburide can reverse one of the earliest abnormalities of carbohydrate metabolism seen in iron-overloaded thalassemia patients, namely, excessive insulin responses to oral glucose (3). In regard to the considerable test-retest variability in plasma insulin responses to oral glucose in normal subjects, it is especially noteworthy that no change or even a modest increase in hyperinsulinemia was seen during the 12 mo before glyburide, whereas the reduction in insulin responses seen at 3 mo was reproduced after 12 mo of glyburide administration. Hyperinsulinemia was corrected in these nondiabetic subjects without adversely affecting oral glucose tolerance. Indeed, if anything, glucose levels tended to be lower during therapy; only relatively low doses of the sulfonylurea agent were required, and the treatment was well tolerated. Moreover, the correction of hyperinsulinemia could not be attributed to changes in body fat, a reduction in iron load, or alterations in hematologic status (Table 2).

We have previously reported that the exaggerated insulin response to glucose in hypertransfused thalassemic patients is due to augmented insulin secretion rather than altered hepatic extraction in insulin (3). Specifically, first- and second-phase Cpeptide responses (a more direct measure of insulin secretion) during the i.v. glucose infusion were found to be increased in thalassemic patients. Because glyburide does not increase and may even decrease hepatic removal of insulin $(9,10)$, it is likely that the restoration of insulin responses to normal after glyburide can be attributed to a reversal of insulin hypersecretion.

In patients with type II diabetes, sulfonylurea agents act, at least in part, by improving sensitivity to insulin (4-6). The observation in our patients that glyburide reduced plasma insulin levels without impairing oral glucose tolerance, as well as the demonstration of increased insulin-stimulated glucose metabolism in most patients during the insulin clamp studies, even after only 3 mo of treatment, is consistent with such a potentiation of insulin action. Although the increase in insulin responsiveness after 3 mo of treatment did not reach statistical significance, the statistical power to demonstrate such a difference was limited by the relatively small number of patients available for study. Overt diabetes mellitus in thalassemia is associated with insulin deficiency. This observation led to the assumption that insulinopenia in these patients is simply a result of B-cell destruction due to iron toxicity to pancreatic islets. However, postmortem studies in patients with iron overload and normal glucose tolerance have found increased B-cell mass (11). These findings, coupled with our recent studies of insulin secretion and action in the prediabetic phase of the disease (3), imply that the development of insulin resistance and compensatory hyperinsulinemia during the second decade of life may also play a role in the pathogenesis of diabetes in thalassemic patients. Chronic hypersecretion of insulin could ultimately result in B-cell exhaustion and thus contribute to insulin deficiency and diabetes, as has been suggested in animal studies. As recently reviewed by Weir et al. (12), reductions in B-cell mass in rats by toxic injury or partial pancreatectomy can result in loss of first-phase insulin release, cause compensatory increases in second-phase insulin secretion, reduce insulin sensitivity, and ultimately lead to B-cell failure and overt diabetes. Sulfonylurea therapy may thus interrupt this pathway by its ability to diminish insulin resistance and in turn reverse the hyperinsulinemic response to glucose seen in nondiabetic thalassemic patients.

Larger, randomized, placebo-controlled prospective clinical trials will be required to establish whether glyburide might provide a means of postponing the development of diabetes in thalassemia. Considering the potential adverse cardiovascular effects of increased circulating insulin levels (13) and the increased cardiac morbidity in thalassemic patients, the ability of glyburide to correct hyperinsulinemia in these patients may itself be beneficial.

Acknowledgments. The authors thank the nursing staff of the Childrens Clinical Research Center of the Yale-New Haven Medical Center for the excellent care given to our patients. We also thank Natalie Hunt of Princess Margaret Hospital in Perth, Western Australia, for her assistance in preparing the manuscript.

\section{REFERENCES}

1. Zurlo MG, De Stefano P, Borgna-Pignatti C, Di Palma A, Piga A, Melevendi C, Di Gregorio F, Burattini MG, Terzoli S 1989 Survival and causes of death in thalassaemia major. Lancet 2:27-30

2. De Sanctis V, Zurlo MG, Senesi E, Boffa C, Cavallo L, Di Gregorio F 1988 Insulin dependent diabetes in thalassaemia. Arch Dis Child 63:58-62

3. Merkel PA, Simonson DC, Amiel SA, Piewe G, Sherwin RS, Pearson HA, Tamborlane WV 1988 Insulin resistance and hyperinsulinemia in patients with thalassemia major treated by hypertransfusion. N Engl J Med 318:809_ 814

4. Simonson DC, Ferrannini E, Bevilacqua S, Smith D, Barrett E, Carlson R, DeFronzo RA 1984 Mechanism of improvement in glucose metabolism after chronic glyburide therapy. Diabetes 33:838-845

5. Greenfield MS, Doberne L, Rosenthal M, Schultz B, Widstrom A, Reaven GM 1982 Effect of sulfonylurea treatment on in vivo insulin secretion and action in patients with non-insulin diabetes mellitus. Diabetes 31:307-312

6. Ward G, Harrison LC, Proietto J, Aitken P, Nankervis A 1985 Glicazide therapy is associated with potentiation of post-binding insulin action in obese, non-insulin dependent diabetic subjects. Diabetes 34:241-245

7. McGuire EAH, Helderman JH, Tobin JD, Andres R, Berman M 1976 Effects of arterial versus venous sampling on analysis of glucose kinetics in man. $\mathrm{J}$ Appl Physiol 41:565-573

8. DeFronzo RA, Tobin JD, Andres R 1979 Glucose clamp technique: a method for quantifying insulin secretion and resistance. Am J Physiol 237:E214E223

9. Almer L-O, Johannson E, Melander A, Wahlin-Boll E 1982 Influence of sulphonylureas on the secretion, disposal and effect of insulin. Eur $J$ Clin Pharmacol 22:27-32

10. Scheen AJ, Lefebvre PJ, Lucyckx AS 1984 Glipizide increases after a standardized breakfast in type 2 diabetic patients. Eur J Clin Pharmacol 26:471-474

11. Rahier JR, Loozen S, Goebbels RM, Abrahem M 1987 The hemochromatotic human pancreas: a quantitative immunohistochemical and ultrastructural study. Diabetologia 30:5-12

12. Weir G, Leahy JL, Bonner-Weir S 1986 Experimental reduction of B-cell mass: implications for the pathogenesis of diabetes. Diabetes Metab Rev 2:125161

13. Zavaroni I, Bonora E, Paghara M, Dall Aglio E, Luchetti L, Bounarro G, Bonati PA, Bergonzani M, Gondi L, Passeri M, Reaven G 1989 Risk factors for coronary artery disease in healthy persons with hyperinsulinemia and normal glucose tolerance. N Engl J Med 320:702-706 